\title{
Decreasing landing forces: effect of instruction
}

\author{
Peter J McNair, Harry Prapavessis, Karen Callender
}

\begin{abstract}
Objective-To examine the effects of instructions related to joint kinematics, auditory stimuli, and imagery on lowering the vertical ground reaction forces associated with landing from a jump.

Study Design-Randomised controlled trial.

Setting-A laboratory in an educational institution.

Subjects-Eighty asymptomatic subjects ( 27 men) with a mean age of 24 years.

Intervention-Subjects were randomly assigned to the following groups: (1) instruction (limb position instructions); (2) auditory cue (listen to impact sounds); (3) imagery (metaphorical); (4) control. Subjects were required to jump from a box 300 $\mathrm{mm}$ in height and land on a force plate. Measures of the ground reaction force were recorded before and after the intervention.

Main Outcome Measure-The peak vertical ground reaction force recorded at footstrike.

Results-The peak vertical ground reaction forces in the technical instruction and auditory groups were significantly less than those of the control group. There was no significant difference between the auditory and technical instruction groups. There was no significant difference between the imagery and control groups.

Conclusions-When an aim of a rehabilitation programme is to minimise forces on the lower limb during landing type activities, the findings support the use of instructions related to kinematics as well as instructions that draw the patient's attention to the sound at impact.

(Br F Sports Med 2000;34:293-296)
\end{abstract}

Keywords: landing; jumping; ground reaction forces; joint; kinematics

Science Department,

University of Auckland

H Prapavessis

Department of

Physical Therapy,

University of Vermont,

Burlington, Vermont,

USA

K Callender

Correspondence to:

Dr P J McNair,

Neuromuscular Research

Unit, School of

Physiotherapy, Auckland

University of Technology,

Private Bag 92006,

Auckland, New Zealand

email:

peter.mcnair@ant.ac.nz

Accepted for publication 10 March 2000 decreased. Essential to the control of motion the activity of muscles. Melvill-Jones and Watt ${ }^{4}$ showed that when subjects were unexpectedly dropped from a $5 \mathrm{~cm}$ height, plantar flexor activity was not sufficient to control dorsiflexion after landing, and subjects invariably experienced uncomfortable jarring as the heel contacted the ground. Landings were relatively more comfortable when subjects were dropped from greater heights, or allowed to activate their muscles before the landing task. These findings provide evidence for the occurrence of preprogrammed muscle action before and during the landing phase as a mechanism for reducing ground reaction forces.

Although it has been shown that ground reaction forces can be decreased by muscle and joint activity, particularly at the knee and ankle, there has been very little research into how instructions related to landing safely are assimilated. An investigation by Ayalon and Ben-Sira ${ }^{5}$ noted that subjects who received feedback of their performance were able to decrease ground reaction forces more effectively than a control group. These authors also noted that providing subjects with visual information on their force time traces was not significantly better than providing verbal information only.

More recently, Prapavessis and $\mathrm{McNair}^{6}$ reported that ground reaction forces could be decreased by $19 \%$ immediately after technical instruction on lower limb kinematics. They commented that further decreases in force may be seen if the subject's attention was drawn to salient cues in the environment-for example, the sound as the feet impact with the landing surface. In this respect, Magill ${ }^{7}$ suggested that subjects require a detectable reference point in the environment to be able to determine immediately the success of their performance. Magill also suggested that the performer may not always be aware of the relation between these reference points and performance success. Hence, one purpose of this study was to examine whether subjects can be taught to decrease their landing forces by drawing their attention to cues, such as the sound associated with landing.

Prapavessis and $\mathrm{McNair}^{6}$ also commented that the use of imagery associated with the intended movement may be effective in improving landing performance. Traditionally, it has been widely acknowledged that imagery rehearsal has the potential to play an important role in the learning and performing of a motor skill. ${ }^{89}$ The literature on the effectiveness of imagery rehearsal, however, has been equivocal - that is, imagery rehearsal has been found to be effective in learning and performing of motor skills only in some instances and under some conditions. ${ }^{10}$ Evidence that not all motor skills benefit equally from imagery rehearsal comes from a meta-analysis under- 
taken by Feltz and Landers. ${ }^{11}$ They found that the size of the imagery effect was larger for predominantly cognitive (symbolic) tasks such as finger maze learning. Landing from a jump in a stable and balanced position is a goal directed skill in which muscle activity must be generated to coordinate three major lower limb joints. ${ }^{1}$ Therefore it was considered to be a skill that has a strong cognitive (symbolic) component and potentially high imagery value. Thus another purpose of this study was to examine whether subjects improve their landing performance through imagery rehearsal.

In summary, given the paucity of information on the acquisition of techniques that could decrease landing forces, the purpose of this study was to examine whether different sets of instruction could assist subjects to land with lower impact forces. These instructions were concerned with lower limb kinematics, an external cue (sound), and imagery rehearsal.

\section{Methods}

SUBJECTS

The sample consisted of 80 subjects ( 27 men and 53 women) whose mean (SD) age was 24 (7) years. All subjects were currently active in recreational activities-for example, soccer, badminton, tennis - for about one or two hours three or four times a week. No subjects were involved in sports involving jumping activities-for example, gymnastics, basketball - and none had a history of significant involvement in sports in which jumping and landing were an important element. No subjects reported any musculoskeletal or neurological conditions that precluded their participation in the study.

PROCEDURES

The institution's ethics committee approved all procedures. To provide baseline data, each subject jumped 8 times from a box $300 \mathrm{~mm}$ in height. This height was chosen to simulate that commonly performed during work, sport, and leisure activities. ${ }^{12}$ Subjects began their jump by stepping outwards off the box with the front leg slightly flexed and the rear leg straight. ${ }^{1}$ They landed in a balanced position on both feet about $300 \mathrm{~mm}$ forward from the box on a force plate. They were instructed to land in a manner that would minimise the stress of the landing. No feedback was given to the subjects or experimenters about their performance. All trials were performed with the subjects barefoot.

Subjects were randomly assigned by computer generated numbers to one of the following groups, and asked to perform a further eight landings.

(1) A technical instruction group: subjects were asked to use the following script to land as softly as possible during their next set of jumps: "When you do your next jump, position yourself on the balls of your feet with bent knees just prior to landing. On landing, lower the heels slowly to the ground and bend the knees until well after the landing".
(2) An auditory cue group: subjects were asked to listen to the sound of their landing and use that information to assist them to land more softly in subsequent landings.

(3) An imagery rehearsal group: these subjects were provided with a metaphoric imagery perspective. They were asked if they could picture one of the following statements: "bubbles floating down toward the ground"; "feathers floating down towards the ground"; "leaves floating down towards the ground"; "snowflakes floating down towards the ground". If they could identify with one of these statements, they were then asked to picture that image and feel like that object when they performed their next series of jumps.

(4) A control group: subjects were asked to use the experience of their first set of jumps to land as softly as possible for their next series of jumps, and thus relied solely on their own feedback systems for information on landing with minimal stress.

\section{INSTRUMENTATION}

Subjects landed on a force plate (Advanced Mechanical Technology Inc, Newton, Massachusetts, USA), from which signals were sampled at $1000 \mathrm{~Hz}$, and relayed to a custom made computerised data acquisition and analysis program. This program established the peak vertical ground reaction force associated with foot contact during the landing task. This measure has been used extensively to examine the magnitude of impact forces during jumping activities. $^{12}{ }^{13}$ Previous work $^{6}$ has shown the reliability of this measure to be high (intraclass correlation coefficient of $0.82, \mathrm{p}<0.05)$. The magnitude of the peak vertical ground reaction force was divided by the subject's body weight, and thus expressed in units of body weight (BW). This normalisation procedure, which is typically used in assessing ground reaction force data, ${ }^{14}$ allowed a comparison to be made across subjects. The mean of the eight landings before and the eight landings after the intervention was used in the statistical analysis.

STATISTICAL ANALYSIS

Statistical analysis was undertaken using the computer program SPSS (SPSS Inc, Chicago, Illinois, USA). An analysis of covariance procedure was used to compare the dependent variable across the different conditions (technical instruction, auditory cue, imagery rehearsal, and control groups). The covariate was the mean of the eight baseline (before training) vertical ground reaction forces. The $\alpha$ level was set at 0.05. A Bonferroni adjustment was applied to planned comparisons to minimise the likelihood of a type I error. The partial $\eta^{2}$ statistic provided estimates of the effect sizes.

\section{Results}

Figure 1 shows the mean (SD) for the peak vertical ground reaction forces across the different conditions. Evaluation of the analysis of covariance assumptions of linearity, homogeneity of regression (slopes), and reliability of covariates were satisfactory. ${ }^{15}$ The analysis of 


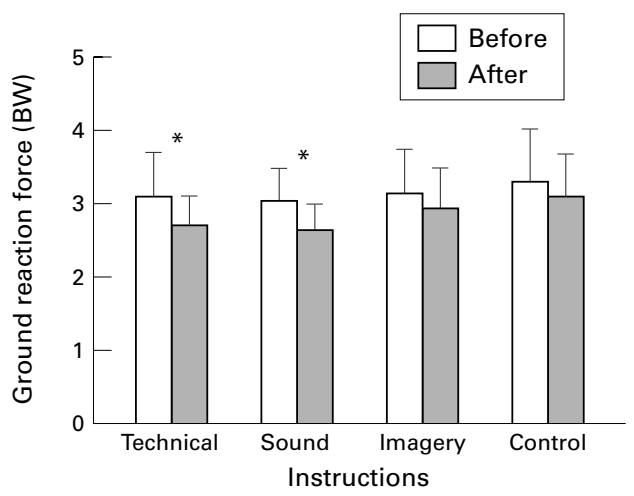

Figure 1 Mean (SD) of vertical ground reaction forces before and after instructions. *Significant difference from control group. BW, body weight.

covariance was significant $(\mathrm{F}(4,93)=4.28)$, and Bonferroni corrected comparisons showed that the technical instruction group differed significantly from the control group (effect size $=0.15$, power $=0.70) \cdot{ }^{16}$ In addition, the auditory cue group differed significantly from the control group (effect size $=0.18$, power $=$ 0.79 ). In both cases, the peak ground reaction force decreased, and the magnitude of the decrease was $0.4 \mathrm{BW}(13 \%)$. The imagery rehearsal group was not significantly different from the control group.

\section{Discussion}

A number of researchers have commented on the potential for lower limb injuries to be sustained when high ground reaction forces are generated during gait activities. ${ }^{2}$ To date, most research examining ground reaction forces has focused on gait, during which the vertical ground reaction forces at footstrike can vary between 1.6 and $2.3 \mathrm{BW}$ across speeds ranging from 3 to $5 \mathrm{~m} / \mathrm{s} .{ }^{17}$ In this study, the mean baseline ground reaction force across all subjects was $3.1 \mathrm{BW}$, which is lower than that reported by McNitt-Gray ${ }^{1}$ and McNair and Marshall, ${ }^{12}$ who noted ground reaction forces of $3.93 \mathrm{BW}$ and $4.6 \mathrm{BW}$ respectively during landing from a similar height.

Our findings showed that instructions related to kinematics led to significantly greater decreases in peak vertical ground reaction forces than found in the imagery and control groups. Although specific limb positions and movements such as landing on the forefoot and bending the knees have been associated with low ground reaction forces, ${ }^{13}$ there is little information available on ability to assimilate instructions for landing with less force. With respect to pedagogy, our findings have important implications. They provide evidence that precise instructions related to the kinematics of the lower limb can lead to a $13 \%$ decrease in peak ground reaction forces, a result that is consistent with the work of Prapavessis and McNair, ${ }^{6}$ who reported that adolescents decreased ground reaction forces by $19 \%$ after being given technical instructions. It has been suggested $^{18}$ that landing from a jump is a fundamental skill that many adults have not mastered. It would be of interest to examine whether the present findings could be repli-

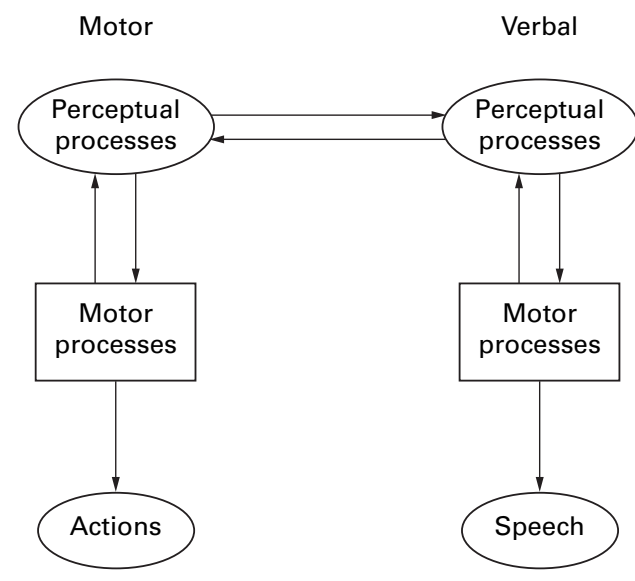

Figure 2 The action-language-imagination model described by Annett. ${ }^{19} 20$

cated with children. The results may assist health and physical education policy makers in the development of their curriculum objectives for motor skills in children.

Our findings also provide evidence that instructions that were focused on an external cue-that is, sound associated with foot impact-led to a more improved landing performance. As discussed above, the sound of the impact may provide an important reference point from which the subject can assess performance. This point is relevant to the clinical setting, where patients and practitioners do not normally have access to equipment allowing the assessment of ground reaction forces.

How verbal instruction (be it technical information related to lower limb kinematics or information from a relevant external cue) works has been examined by Annett, ${ }^{19}{ }^{20}$ who described an action-language-imagination model. In this model (fig 2), there are two independent encoding systems by which a learner can acquire information about a skill: motor (the production of action) and verbal (the production of language). These two systems are linked by a perceptual-processing bridge, referred to as the action-language bridge, which makes it possible for the learner to describe an action, generate an action, and act on verbal instructions. ${ }^{21}$ According to the action-language-imagination model, both sets of instruction help participants generate a symbolic representation (image) of the most pertinent information related to learning the movement. The image is then translated into a verbal code that can be recalled.

Our findings show that imagery rehearsal was not part of an effective strategy to assist individuals to land with less force. This finding may be related to the type of imagery that was presented to the subjects. Overby et $a^{l^{2}}$ investigated the extent to which dance teachers and coaches engaged in imagery rehearsal. They found that respondents used kinaesthetic, visual, and metaphoric imagery to assist their dancers and athletes with learning and performing. According to the dance teachers and figure skating coaches sampled, a good metaphor would often help "crystallise" a specific 
movement needed for successful execution of a skill. To date, there is no unequivocal evidence to suggest that the metaphoric imagery perspective is inferior to either the kinaesthetic or visual perspective. ${ }^{22}$ Perhaps, if the metaphoric imagery used in this study had the subject involved in the metaphoric experience-for example, "imagine a parachute opens up just as you take off from the box"-rather than imagining themselves as another object-for example a feather - a different result may have been obtained. Another reason why imagery rehearsal was not part of an effective strategy to assist subjects to land with less force may be related to individual differences in imagery ability. Although all subjects in the imagery group stated that they could relate to the metaphors presented to them, there is some evidence that a dispositional tendency to image influences imagery effectiveness. ${ }^{23}$ Finally, it may be that the metaphors used in this study should have been more related to the landing phase of the task rather than the flight phase. These issues warrant future attention.

The findings of this study also have relevance to clinical practice. For instance, in anterior cruciate ligament deficient subjects, McNair and Marshall ${ }^{12}$ noted a correlation of 0.87 between anterior tibial acceleration and vertical ground reaction forces. They suggested that lowering ground reaction forces may lead to decreased instability of the knee. Other authors ${ }^{3}$ have linked impact forces to the onset and development of osteoarthritis, and have suggested that lowering these forces may limit the progressive degeneration of joints. During rehabilitation, some injuries such as stress fractures also require the patient to modify their gait activities, for instance, by changing the surfaces on which they perform activities. ${ }^{24}$ The use of effective instructions and auditory cues would also assist the patient to lessen the stresses on their injury site.

The quadriceps and plantarflexor muscles work eccentrically to slow the upper body's momentum at footstrike. ${ }^{25}$ If subjects are to perform the instructions related to joint movements successfully, sufficient strength and control of the quadriceps and plantarflexor muscles is essential. ${ }^{26} \mathrm{~A}$ deficiency in these factors is likely to lead to higher landing forces, particularly after repeated landings. Therefore, from a clinical perspective, when subjects are learning these landing techniques, it may be beneficial to include a training programme aimed at improving the performance capabilities of these muscles.

\section{CONCLUSIONS}

This study provides further evidence for the inclusion of instructions related to the kinematics of the knee and ankle joints when sub- jects are landing from a jump. The findings indicate that, within a single session, subjects can assimilate these instructions effectively to lower their vertical ground reaction forces. In addition, drawing attention to external cues such as the sound generated when landing can also lower vertical ground reaction forces.

This work was presented in October 1998 at the Sports Medicine Australia Annual Conference, Adelaide, Australia.

1 McNitt-Gray J. Kinematics and impulse characteristics of drop landings from three heights. International f Sports Biomechanics 1991;7:201-23.

2 Nigg BM, Denoth J, Kerr B, et al. Load, sports shoes and playing surfaces. In: Frederick EC, ed. Sports shoes and playing surfaces. Champaign, IL: Human Kinetics, 1984:123.

3 Mizrahi J, Susak Z. In-vivo elastic and damping responses of the human leg to impact forces. F Biomech Eng 1982;104: 63-6

4 Melvill-Jones G, Watt DGS. Muscular control of landing from unexpected falls in man. F Physiol 1971;219:729-37.

5 Ayalon A, Ben-Sira D. The mechanical changes during learning of a landing skill through various feedback methods. In: de Groot $\mathrm{G}$, Hollander A, Huijing P, et al, eds. Biomechanics XI-B. Amsterdam: Free University Press, 1988:689-93.

6 Prapavessis H, McNair PJ. Effects of sensory and augmented feedback on ground reaction forces when landing from a jump. F Orthop Sports Phys Ther 1999;29:352-6.

7 Magill R. Motor learning concepts and applications. 4th ed. Dubuque: Brown and Benchmark Ltd, 1993.

8 Richardson A. Mental practice: a review and discussion (Part 1). Res Q 1967;38:98-107.

9 Corbin CB. Mental practice. In: Morgan WP, ed. Ergogenic aids and muscular performance. New York: Academic Press, 1992:94-118.

10 Hall C, Buckolz E, Fishburne G. Imagery and the acquisition of a motor skill. Canadian fournal of Sport Science 1992;17:19-27.

11 Feltz DL, Landers DM. The effects of mental practice on motor skills learning and performance: a meta-analysis. fournal of Sport Psychology 1993;5:25-57.

12 McNair P, Marshall R. Landing characteristics in subjects with normal and anterior cruciate ligament deficient knee with normal and anterior cruciate ligament de

13 Dufek J, Bates B. The evaluation and prediction of impact forces during landings. Med Sci Sports Exerc 1990;22:370-

14 Miller D. Ground reaction forces in distance running. In: Cavanagh P, ed. Biomechanics of distance running. Champaign, IL: Human Kinetics, 1990:203-24.

15 Fleiss J. The design and analysis of clinical experiments. New York: John Wiley and Sons, 1986.

16 Tabachnick B, Fidell L. Using multivariate statistics. New York: Harper Collins Inc, 1989:344-5.

17 Munro C, Miller D, Fuglevand A. Ground reaction forces in running. $\mathcal{F}$ Biomech 1987;20:147-55.

18 Lees A. Methods of impact absorption when landing from a jump. Engineering in Medicine 1981;10:207-11.

19 Annett J. The learning of motor skills: sports science and ergonomics perspectives. Ergonomics 1994;37:5-15.

20 Annett J. On knowing how to do things. Cognitive Brain Research 1996;3:65-9.

21 Hall C, Moore J, Annett J, Rogers W. Recalling demonstrated and guided movments using imaginary and verbal rehearsal strategies. Res $Q$ Exerc Sports 1997;68:136-44.

22 Overby LY, Hall C, Haslam I. A comparison of imagery used by dance teachers, figure skating coaches and soccer coaches. Imagination, Cognition and Personality 1998;17: 323-37.

23 Goss S, Hall C, Buckolz E, et al. Imagery ability and the acquisition and retention of movements. Memory and $\operatorname{Cog}$ nition 1986;14:469-77.

24 Brukner P, Bennell K. Stress fractures in female athletes. Diagnosis, management and rehabilitation. Sports Med Diagnosis, mana

25 Devita P, Skelly W. Effect of landing stiffness on joint kinetics and energetics in the lower extremity. Med Sci Sports Exerc 1992;24:108-15

26 Jefferson R, Radin E, O'Connor J. The role of the quadriceps in controlling impulsive forces around heelstrike. Proceedings of the Institute of Mechanical Engineering. Part H. Fournal of Engineering in Medicine 1990;204:21-8.

Take home message

When instructing people how to land safely from a jump, draw their attention to the sound of their landing as well as providing concise instructions related to lower limb motion. 